\title{
Induced Shear Failure by Temperature Reduction at Uni-axial Strain Conditions
}

\author{
Voake, T.; Nermoen, A.; Korsnes, R.I.; Fabricius, Ida Lykke
}

Published in:

19th European Symposium on Improved Oil Recovery 2017: Sustainable IOR in a Low Oil Price World

Publication date:

2017

Document Version

Publisher's PDF, also known as Version of record

Link back to DTU Orbit

Citation (APA):

Voake, T., Nermoen, A., Korsnes, R. I., \& Fabricius, I. L. (2017). Induced Shear Failure by Temperature Reduction at Uni-axial Strain Conditions. In 19th European Symposium on Improved Oil Recovery 2017: Sustainable IOR in a Low Oil Price World [TU P027] European Association of Geoscientists and Engineers.

\section{General rights}

Copyright and moral rights for the publications made accessible in the public portal are retained by the authors and/or other copyright owners and it is a condition of accessing publications that users recognise and abide by the legal requirements associated with these rights.

- Users may download and print one copy of any publication from the public portal for the purpose of private study or research.

- You may not further distribute the material or use it for any profit-making activity or commercial gain

- You may freely distribute the URL identifying the publication in the public portal 


\title{
Tu P027
}

\section{Induced Shear Failure by Temperature Reduction at Uni-axial Strain Conditions}

\author{
T. Voake* (University of Stavanger, IOR Centre of Norway), A. Nermoen \\ (University of Stavanger, IOR Centre of Norway), R.I. Korsnes (University \\ of Stavanger) \& I.L. Fabricius (Technical University of Denmark)
}

\section{SUMMARY}

This study improvises uniaxial strain condition during cooling by keeping constant overburden, and adjusting radial stress at cooler temperatures in order to re-establish the same radial dimensions prior to cooling. The amount of radial stress reduction by thermal contraction could be sufficient to trigger shear failure. Experiments are performed on Mons chalk and Kansas chalk so the role of induration can be assessed. Calcite thermal expansion is highly anisotropic. Weakening caused by temperature fluctuation could give insight to what gives chalk its strength, cementation, or repulsive electrostatic forces. For each chalk type, shear failure line is determined. The samples are heated to $90 \mathrm{oC}$ and loaded to $70 \%$ of the axial stress required to induce shear failure. Then the temperature is reduced by $60^{\circ} \mathrm{C}$. The change in confining pressure necessary to restore zero radial strain is estimated. The two chalks show different behaviour. Mons demonstrates this cooling would induce shear failure, but has no significant effect on its strength. Kansas, is able to restore uniaxial strain conditions without shear failure. The strength of the Kansas sample was unaffected, however the change in confining pressure needed to restore the uniaxial strain condition decreased with each additional cycle, indicating changing elastic properties. 


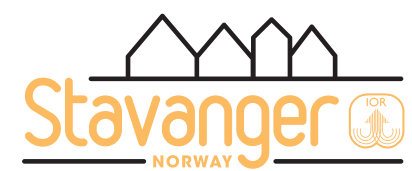

\section{The National \\ IOR Centre \\ of Norway}

\section{Introduction}

This project aimed at to better understand chalk reservoir stability during water injection. Enhanced oil recovery techniques (EOR) increase the amount of oil that can be extracted from an oil field. New discoveries are becoming harder and more costly to find (Sahrabi et al., 2011), and therefore a lot of research has focused on the recovering techniques to make better use of the discovered reserves by increasing recovery factors. However, sometimes the EOR methods and injected fluid can destabilize reservoirs. A well-known example is the Ekofisk field in the North Sea. Ekofisk is a chalk reservoir that was compacted during production and water flooding, leading to sea floor subsidence (Nagel, 2000). Chalk is a carbonate rock whose particles originate from skeletons of coccoliths algae, mostly made of calcite grains. The grains are held together by contact cement at short distances counteracted by electrostatic repulsion at intermediate distance that is dependent on temperature and brine composition (Nermoen et al., 2016). One factor that could lead to reservoir destabilization, that may have been overlooked so far, is the effect of temperature variation. As cold water is injected into a hot reservoir during water flooding, calcite crystals will be subjected to thermal contraction, and conversely to expansion when reservoir temperature is re-established. Because the thermal expansion coefficient of calcite crystals is strongly anisotropic $\left(23.6 \cdot 10^{-6} \mathrm{~K}^{-1}\right.$ along the c-axis and $-5.2 \cdot 10^{-6} \mathrm{~K}^{-1}$ along a-axes (Rosenholtz and Smith, 1950)), temperature fluctuations can cause considerable deformation of calcitic rocks. Many common examples include the degradation of marble cladding of buildings and monuments which are mineralogically equivalent to chalk but with a different chemical micro-structure, such as the Finlandia Hall in Helsinki which consists of Carrara marble (Royer-Carfagni, 1999).

Many studies have been conducted on how the injected EOR fluid composition which can, for example alter reservoir wettability, a property that defines which fluid preferentially stick to rock surfaces and thereby control the flow of oil and water. The aim of these studies was to extract the previously immobile oil. Other EOR studies focus on enhancing the volumetric sweep by diverging fluids to unswept regions of the reservoirs. Our focus is on understanding how the mechanical properties of chalks are sensitive to temperature changes. Lee et al., 1996 observed that the compressive strength of igneous and metamorphic rocks, as well as Young's and bulk modulus decrease with increasing temperature. These authors conducted experiments on granite and gneiss with increasing temperatures from $25^{\circ} \mathrm{C}$ to $200^{\circ} \mathrm{C}$ and report rock strength reduction in both uniaxial and triaxial tests. Similar results were obtained by dos Reis (2012) who studied Polymer mortars, which are used as building materials, and where increasing temperature from room temperature to $90^{\circ} \mathrm{C}$ resulted in decrease of material compressive strength. Results from Huang and Xia (2015) and Yu et al. (2015) on sandstone mechanical properties suggest strength increase with temperature rise from $20^{\circ} \mathrm{C}$ to $200^{\circ} \mathrm{C}$ as a result of original crack closures, but upon further heating to $600^{\circ} \mathrm{C}$, weakening was observed. Finally, a study by Madland et al. (2002) on strength comparison of high porosity chalk at $20^{\circ} \mathrm{C}$ and $90^{\circ} \mathrm{C}$ was conducted using Brazilian, uniaxial, and triaxial tests, and reported strength reduction, along with $30 \%$ reduction of elastic modulus with temperature increase from 20 to $90^{\circ} \mathrm{C}$.

This paper concentrates on quantifying how the radial stress was affected by decreased temperature for two different types of chalk. The purpose was to find to what degree Lame's parameter $\lambda$ decrease upon cooling. This is done by measuring how much the horizontal side stress has to be reduced to keep a constant diameter when a chalk sample was cooled from $90^{\circ} \mathrm{C}$ to $30^{\circ} \mathrm{C}$. The reduction of side stress was performed at constant overburden axial stress and pore pressure. The tests were performed with an overburden stress equal to $70 \%$ of the stress required to induce shear failure.

The strength of a rock is commonly defined from the relation between stress and strain and the stress level at which it fails. To calculate a shear failure line, a series of triaxial compression tests were performed at different confining pressures. The effective radial stress $\sigma_{r}{ }^{\prime}$ relates to the effective confining pressure $P_{\text {conf }}$, as:

$$
\sigma_{r}^{\prime}=P_{\text {conf }}-\alpha P_{\text {pore }}
$$


where $P_{\text {pore }}$ is pore pressure and $\alpha$ is the Biot coefficient which in the absence of shear velocity data can be estimated from P-wave velocity of the dry sample, $v_{p}$ and frame density, $\rho_{d r y}$, as:

$$
\begin{gathered}
\alpha \approx 1-\frac{M_{\text {dry }}}{M_{\min }}, \\
M_{\text {dry }}=v_{p_{-} d r y}^{2} \rho_{d r y}, \text { and } \\
M_{\text {min }}=K_{\text {calcite }}+\frac{4 G_{\text {calcite }}}{3},
\end{gathered}
$$

where $K_{\text {calcite }}=70.8 \mathrm{GPa}$ and $G_{\text {calcite }}=30.3 \mathrm{GPa}$ (Citations in Mavko et al. 2008).

The effective axial stress is calculated using,

$$
\sigma_{z}^{\prime}=\sigma_{r}+f\left(P_{\text {pist }} \cdot m\right)-\alpha P_{\text {pore }},
$$

where $f$ is an area factor relating the cross sectional area of the chamber providing the hydraulic pressure, $P_{p i s t}$, of the piston to the cross sectional area of the sample and $P_{\text {fric }}$ which is measured during initial piston movement and is round 0.3 MPa. The strain, $\varepsilon$, of a rock is calculated form the original length $\left(L_{0}\right)$ and diameter $\left(D_{0}\right)$ of the sample, and the resulting length $L$ and diameter $D$ during the test,

$$
\varepsilon_{z}=-\frac{L-L_{0}}{L}, \text { and } \varepsilon_{r}=-\frac{D-D_{0}}{D}
$$

For cylindrical coordinate system of linearly elastic, homogeneous and isotropic materials, Hooke's law describes the relation between stress and strain by,

$$
\begin{gathered}
E \varepsilon_{r}=(1-v) \sigma_{r}^{\prime}-v \sigma_{z}^{\prime}, \text { and } \\
E \varepsilon_{z}=\sigma_{z}^{\prime}-2 v \sigma_{r}^{\prime} .
\end{gathered}
$$

Hence, the stress changes would lead to changes in strain, so Eq. 7-8 can be rewritten as,

$$
\begin{gathered}
E \delta \varepsilon_{r}=(1-v) \delta \sigma_{r}^{\prime}-v \delta \sigma_{z}^{\prime}, \text { and } \\
E \delta \varepsilon_{z}=\delta \sigma_{z}^{\prime}-2 v \delta \sigma_{r}^{\prime} .
\end{gathered}
$$

Further, if constant overburden is assumed, and hence $\delta \sigma_{z}^{\prime}=0$, the equations can be further simplified, and the change in radial stress $\delta \sigma_{r}^{\prime}$ calculated as following,

$$
\begin{gathered}
\delta \sigma_{r}^{\prime}=\frac{E \delta \varepsilon_{r}}{(1-v)}, \text { and } \\
\delta \sigma_{r}^{\prime}=-\frac{E \delta \varepsilon_{z}}{2 v} .
\end{gathered}
$$

The strain induced by cooling depends on linear thermal expansion coefficient $K_{T}$, and the quantity of temperature change $\Delta T$,

$$
\varepsilon_{r}=K_{T}^{r} \Delta T
$$

During axial loading with constant side stress, the Poisson's ratio $v$ relates the observed axial and radial strains through,

$$
v=-\frac{\varepsilon_{r}}{\varepsilon_{z}}
$$

From the stress-strain diagram, one can obtain elastic property using Eq. 15. Bulk modulus $K_{\text {bulk }}$ is measured during hydrostatic loading $\sigma_{\text {hyd }}=\sigma_{r}=\sigma_{z}$ (only confining pressure acting on the sample, i.e. $\left.P_{\text {pist }}=P_{\text {fric }}\right)$,

$$
K_{\text {bulk }}=\frac{\sigma_{\text {hyd }}}{\varepsilon_{\text {vol }}}
$$

whereas, for cylindrical samples $\varepsilon_{v o l} \simeq 2 \varepsilon_{r}+\varepsilon_{z}$, when higher order terms are omitted. 


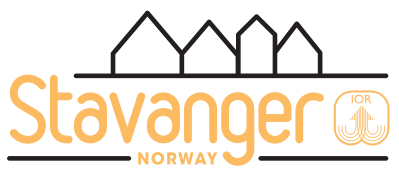

Similarly, Young's modulus $E$, is estimated from the slope in the overburden stress as a function of axial strain during axial loading with constant radial stress,

$$
E=\frac{\sigma_{z}^{\prime}}{\varepsilon_{z}}
$$

The $p-q$ diagram (Figure 1) is conventionally used to display sample failure data, which compares maximum shear stress $q$ with mean effective stress $p$ (Eq. 17-18). A stress path can be traced as a line in the $p-q$ plot, and failure occurs once a failure line is crossed. The combinations of $p$ and $q$ are particularly useful since both are invariant properties of stress tensor such that the position of the failure line can be used in any geotechnical calculation (see discussion in Fjær et al., 2008). Multiple shear failure tests at different confining stresses were performed in order to plot the shear failure line.

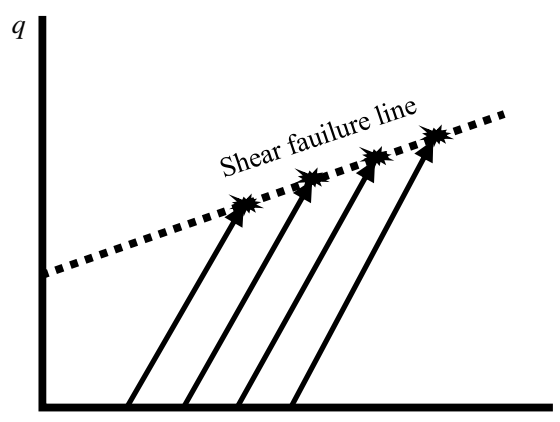

$p$

Figure 1 p-q diagram and direction of deviatoric loading at different confining pressures until shear failure line is reach and the sample fails.

$$
\begin{gathered}
q=\sigma_{z}^{\prime}-\sigma_{r}^{\prime} \\
p=1 / 3\left(2 \sigma_{r}^{\prime}+\sigma_{z}^{\prime}\right)
\end{gathered}
$$

This project investigates how, after contraction due to cooling from reservoir temperatures, the amount by which side stress acting on the tested material must be reduced in order to re-establish the diameter of the sample prior to cooling, and whether the change of temperature would be sufficient to cause crossing of the failure line. In addition, the project compares how two different chalks behave for the same given conditions.

\section{Material}

Two different outcrop chalks with different degrees of induration were used. Properties of the two test samples are listed in Table 1. Porosity and solid density were calculated from dry weight and wet weight obtained from saturating the samples with distilled water in a vacuum chamber. Permeability was determined by Darcy's law, using transducers at the triaxial cell to measure pore pressure gradients.

Table 1 Physical properties of samples tested in this study.

\begin{tabular}{ccccccccc}
\hline Sample & $\begin{array}{c}\text { Chalk } \\
\text { type }\end{array}$ & $\begin{array}{c}\text { Diameter } \\
(\mathbf{m m})\end{array}$ & $\begin{array}{c}\text { Length } \\
(\mathbf{m m})\end{array}$ & $\begin{array}{c}\text { Porosity } \\
(\boldsymbol{\%})\end{array}$ & $\begin{array}{c}\text { Solid } \\
\text { density }\end{array}$ & $\begin{array}{c}\text { Permeability } \\
(\mathbf{m D})\end{array}$ & $\begin{array}{c}\mathbf{v}_{\mathbf{p} \_d r y} \\
(\mathbf{m} / \mathbf{s})\end{array}$ & $\begin{array}{c}\text { Biot } \\
\text { coef. }\end{array}$ \\
\hline M-10b & Mons & 38.10 & 73.41 & 41.1 & 2.69 & 0.53 & 2225 & 0.93 \\
K-21a & Kansas & 38.11 & 76.20 & 35.8 & 2.71 & 0.48 & 3060 & 0.85 \\
\hline
\end{tabular}

The Mons chalk sample from Trivières quarry has a calcite content of approximately $99 \%$ and a coccolith mudstone texture. Richard et al. (2005) described Mons chalk as more coccolith fragments than intact coccoliths, and prominent "point-contact fabric" (contact cement) corresponding to the observed induration of $\mathrm{H} 2$. 


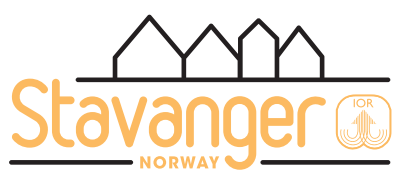

The sample of Kansas chalk has a carbonate content of 97\%, and wackestone texture. Cementation and recrystallization are common, which gives grains angular shapes (Megawati et al., 2015) and an induration of $\mathrm{H} 3$.

The fluid used in the reported experiments was calcite equilibrated water. The equilibrium water was made by dissolving chalk pieces in distilled water, and then allowed to settle for a day at room temperature. Finally, the solution was filtered using a $0.65 \mu \mathrm{m}$ filter.

\section{Method}

Mechanical testing of the samples was performed in a triaxial cell (Figure 2). The cell is equipped with a $1000 \mathrm{~W}$ heating jacket controlled by a Omron E5CN PID connected to a Pt-100 RDT resistance temperature detector inside the cell. The precision of the temperature control is approx. $\pm 0.1^{\circ} \mathrm{C}$. Three different pumps were connected to the cell, so injection flow rate, confining and piston pressure can be controlled individually through a LabVIEW routine. A back pressure regulator connects on the outlet side of the sample to ensure constant pore pressure, which was set to $0.7 \mathrm{MPa}$. Confining and piston pressures were applied using hydraulic pumps (Teledyne Isco Syringe Pump model 260D and Quizix model QX-20000 HC pump), while injection flow rate used a Gilson Pump (model 307 HPLC). Vertical displacement of the axial length of the core was measured both externally and internally by two different LVDT's (Low Voltage Displacement Transducer, MHR 500 for external and MHR 250 for internal from Measurments Specialties ${ }^{\mathrm{TM}}$ ). Radial deformation was measured using an extensometer (the circumference changes were detected by LVDT MHR 100 from Measurments Specialties ${ }^{\mathrm{TM}}$ ).
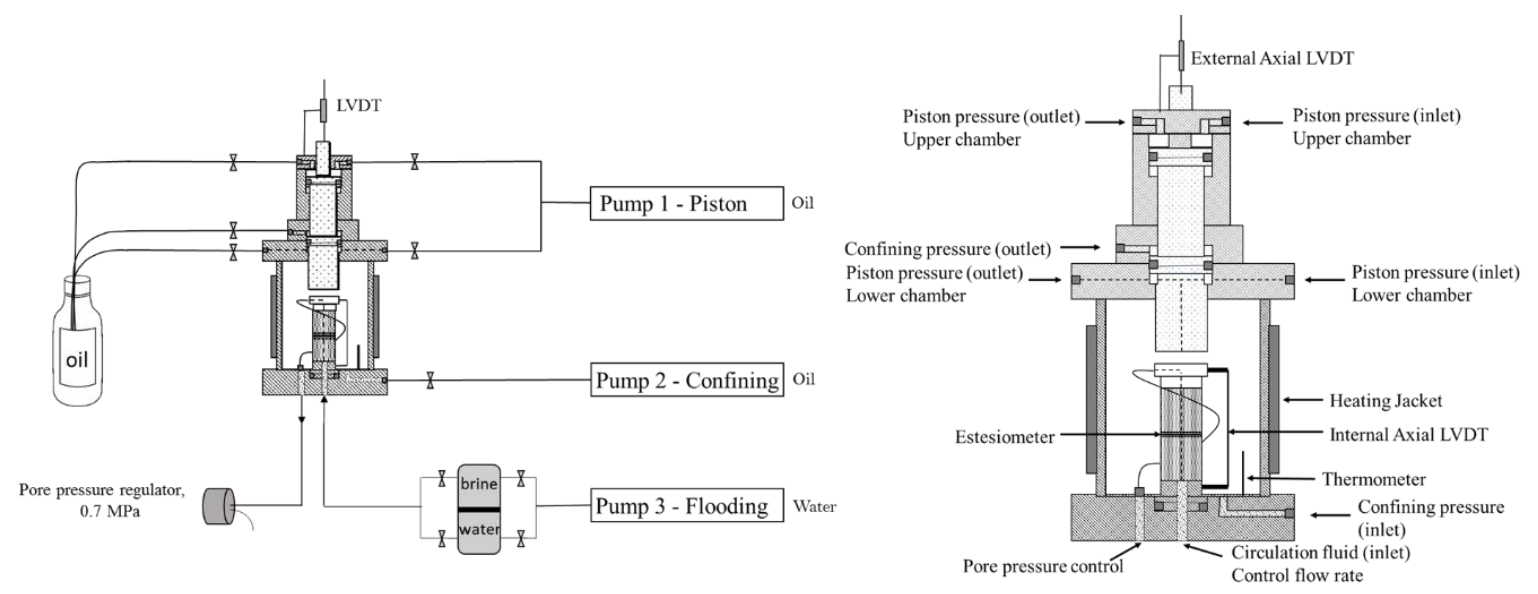

Figure 2 Equipment set up.

Tests determining the shear failure line

Shear failure tests were performed on samples from the same chalk block at different confining pressures. Four different confining pressures were used and the axial stress was increased to failure. Each side stress was tested twice to ensure repeatability of the results. In total, the results of eight individual core tests were used to obtain the shear failure line. The tested confining stresses were 0.8 $\mathrm{MPa}, 1.2 \mathrm{MPa}, 2 \mathrm{MPa}$, and $3 \mathrm{MPa}$. All tests were performed at $30^{\circ} \mathrm{C}$. Each experiment was performed according to following procedure:

- Confining pressure was loaded to $0.5 \mathrm{MPa}$ (apart for the tests at $0.8 \mathrm{MPa}$ confining pressure, where the initial loading was set to $0.1 \mathrm{MPa}$ ).

- Samples were flooded with calcite equilibrium water to measure permeability. 
- Simultaneously, confining and pore pressure were increased to 1.2 $\mathrm{MPa}$ and 0.7 MPa respectively (apart the tests at $\sigma_{r}=0.8 \mathrm{MPa}$, where confining and pore pressure was increased to 0.8 and $0.3 \mathrm{MPa}$ ).

- The temperature was set to $30^{\circ} \mathrm{C}$ and the samples were left until the extensometer obtained a stable reading.

- Piston lowered to touch the sample providing piston friction $\left(P_{\text {fric }}\right)$ measurement.

- Tests at $0.8 \mathrm{MPa}$ and 1.2 MPa were already at the desired confining pressures. For the tests at $2 \mathrm{MPa}$ and $3 \mathrm{MPa}$, the confining pressure was loaded to $2 \mathrm{MPa}$ and $3 \mathrm{MPa}$ at the rate of 0.03 $\mathrm{MPa} / \mathrm{min}$.

- Deviatoric loading was performed by increasing the piston pressure at a rate of $0.03 \mathrm{MPa} / \mathrm{min}$ from zero hydraulic pressure until failure. The $p$ and $q$ values were calculated using the confining pressure at which the loading was performed and axial pressure which the core failed.

\section{Induced shear failure by cooling test}

The aim of this experiment was to measure how much side stress needs to be reduced in order to maintain the same diameter of the sample once temperature was decreased from $90^{\circ} \mathrm{C}$ to $30^{\circ} \mathrm{C}$. The side stress reduction occurred with constant overburden weight (i.e. $\sigma_{z}$ const), and to evaluate if this stress would be sufficient to induce shear failure. The deviatoric tests were chosen to be performed at $\sigma_{r}=2$ $\mathrm{MPa}$. Before the temperature reduction from 90 to $30^{\circ} \mathrm{C}$, the axial stress was chosen to be set to $70 \%$ of the value required to induce shear failure. This yield overburden value of $\sigma_{z}^{\prime}=5.3 \mathrm{MPa}$ for Mons chalk and $\sigma_{z}^{\prime}=11.8 \mathrm{MPa}$ for Kansas chalk. The experimental steps were:

- Confining pressure loaded to 0.5 MPa.

- Saturated samples flooded with calcitic water to measure the differential pressure.

- Simultaneous increase of confining and pore pressure to $1.2 \mathrm{MPa}$ and $0.7 \mathrm{MPa}$, respectively.

- Set temperature to $90^{\circ} \mathrm{C}$ and the experiments were left until the diameter stabilised (between 12 days).

- Piston was lowered to touch the sample. During lowering of the piston friction $\left(P_{\text {fric }}\right)$ could be measured.

- Hydrostatic loading was performed from 1.2 to $2 \mathrm{MPa}$ confining pressure at a rate of 0.03 $\mathrm{MPa} / \mathrm{min}$.

- The axial stress was increased to $70 \%$ of the shear strength.

- A Labview program that ensures pump control, monitoring and data save, was set up to constant overburden mode such that the piston pressure varied according to $\sigma_{r}$ using Eq. 5. The test was left to rest for approximately 24 hours, such that a stable diameter was attained.

- Reduced temperature from $90^{\circ} \mathrm{C}$ to $30^{\circ} \mathrm{C}$.

- Confining pressure lowered from $2 \mathrm{MPa}$ to $0.8 \mathrm{MPa}$ in 36 minutes for Mons and 72 minutes for Kansas, or until the target diameter was reached.

- Confining pressure raised from 0.8 MPa to $2 \mathrm{MPa}$ in 36 minutes and temperature increased back to $90^{\circ} \mathrm{C}$.

- Last three steps were repeated two more times to investigate the impact of how the mechanical properties of the core reacted to the temperature and stress cyclic behaviour.

- After the last cycle, the sample was deviatoric loaded by increasing the axial stress until failure at $\sigma_{r}=0.8 \mathrm{MPa}$.

\section{Results}

The results section is divided into two parts. First, with the aim of loading the sample to $70 \%$ of the axial stress required to induce shear failure requires the shear failure line to be known. The results of 


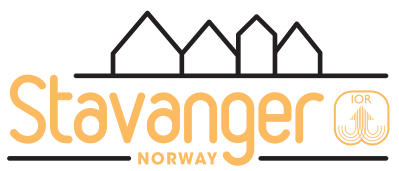

\section{The National \\ IOR Centre \\ of Norway

eight samples at four different confining pressures for each chalk type are shown here. Second, the dependence of side stress on temperature is initially calculated theoretically using Hooke's law and elastic properties of the sample. Then the experimental results are reported.

\section{$\underline{\text { Shear failure line }}$}

The shear failure line was obtained from eight tests for each chalk type. Samples used for this calculation were from the same blocks as the samples used for the side stress reduction test. The results of eight different samples for each chalk type are presented in Table $\mathbf{2}$ and the shear failure lines are visualized at Figure 3. Both $p$ and $q$ values are representative of the peak stress points.

Table 2 Mechanical test results for samples used to plot shear failure lines for Mons and Kansas chalks

\begin{tabular}{c|ccc|ccc}
\hline $\begin{array}{c}\text { Conf. } \\
\text { pressure }\end{array}$ & Sample & $\boldsymbol{p}$ & $\boldsymbol{q}$ & Sample & $\boldsymbol{p}$ & $\boldsymbol{q}$ \\
\hline 0.8 & M-10a & 1.8 & 5.1 & K-20a & 4.4 & 12.5 \\
0.8 & M-8 & 1.9 & 5.1 & K-21b & 4.1 & 11.6 \\
1.2 & M-4b & 2.7 & 6.2 & K-30a & 4.7 & 12.3 \\
1.2 & M-9b & 2.6 & 5.9 & K-29b & 5.7 & 15.2 \\
2.0 & M-5a & 3.5 & 6.3 & K-19b & 6.8 & 16.2 \\
2.0 & M-5b & 3.2 & 5.2 & K-25a & 6.3 & 14.6 \\
3.0 & M-3 & 4.7 & 6.8 & K-25b & 8.2 & 17.4 \\
3.0 & M-7 & 4.6 & 6.7 & K-29a & 8.2 & 17.4 \\
\hline & & & Stan. dev & & & Stan. dev \\
& Slope & 0.534 & 0.144 & Slope & 1.375 & 0.128 \\
& Cohesion & 4.236 & 0.471 & Cohesion & 6.344 & 0.796 \\
\hline
\end{tabular}
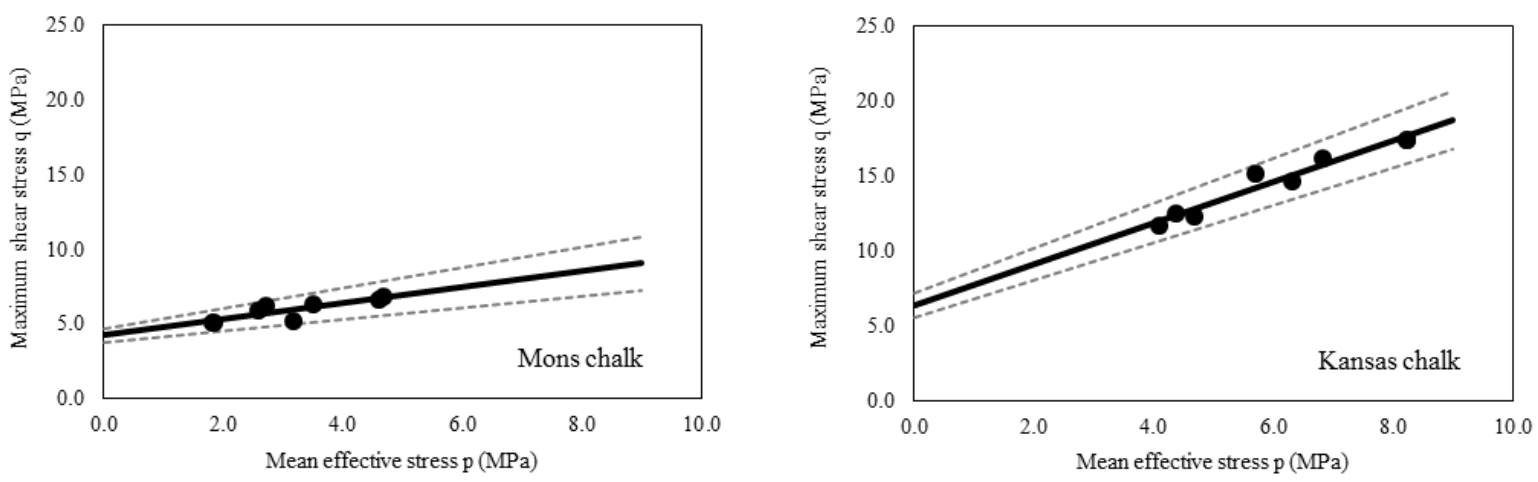

Figure 3 p-q shear failure line diagram for Mons and Kansas chalk.

Induced shear failure by cooling test

Three cooling cycles were performed on each of the two cores. The experiments had to be performed in steps and stable readings had to be gained, since significant transient temperature dependent behaviour of the radial strain was observed. After the core diameter had stabilized at $30^{\circ} \mathrm{C}$, confining pressure was lowered in order to match the core diameter reduction due to cooling. Figure 4 displays the test history of the two core tests and how temperature and side stress was varied along with radial strains (black line in Figure 4). The Mons sample almost accumulates zero strain with temperature cycles, while Kansas sample keeps accumulating strain with diameter increasing after each heating and cooling cycle. 


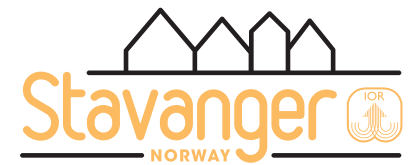

a)

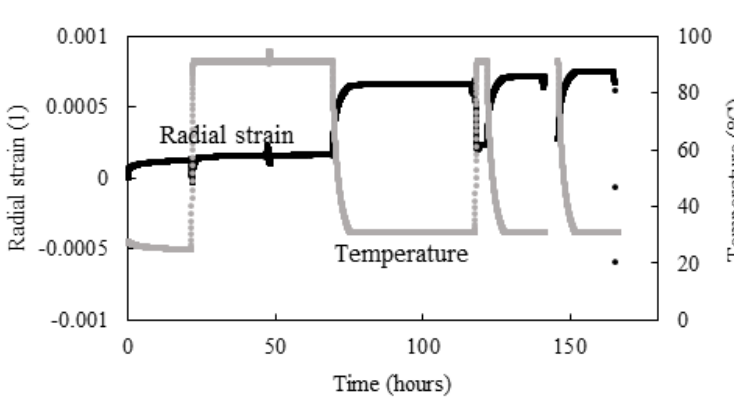

c)

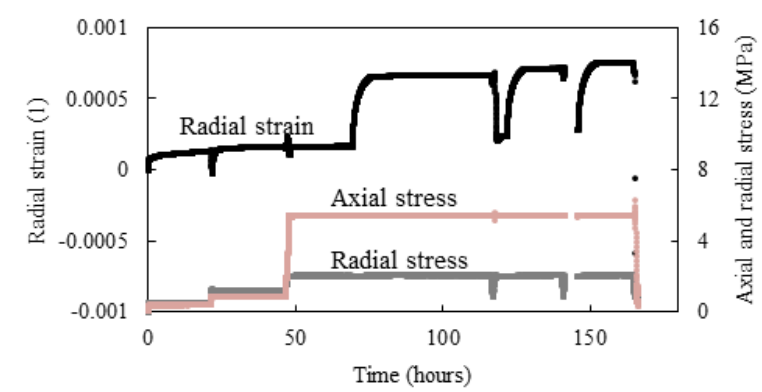

The National

IOR Centre

of Norway

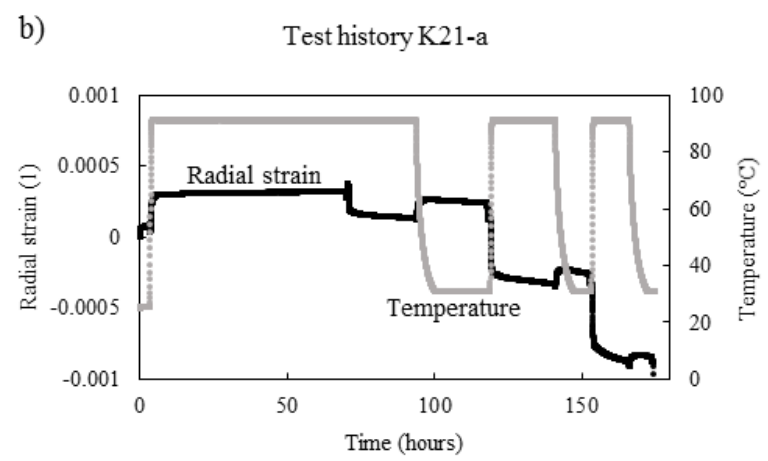

d)



Figure 4 Test history for Mons $(a, c)$ and Kansas $(b, d)$, radial strain (black) is compared with temperature changes $(a, b)$ and stress changes $(c, d)$.

Within the elastic domain, the amount of side stress reduction required to regain the circumferential diameter relied on the stiffness parameters. Young's modulus of the samples was measured during experimental loading to $70 \%$ of the axial stress required to induce shear failure. Bulk modulus was obtained from literature (Megawati et al., 2015), and Poisson's ratio was calculated using

$$
E=3 K(1-2 v)
$$

In Table 3 the theoretical value of the confining stress reduction was calculated using a combination of Eq. 11 and Eq. 13. Using the experimental data, thermal contraction $K_{T}^{r}$ for Mons chalk was calculated to be $8.4 \cdot 10^{-6}, 8.0 \cdot 10^{-6}$ and $7.9 \cdot 10^{-6} \mathrm{~K}^{-1}$ for the three cycles. However, for Kansas chalk the thermal coefficient varied from $1.8 \cdot 10^{-6}$, to $1.2 \cdot 10^{-7}$, and finally $5.5 \cdot 10^{-7} \mathrm{~K}^{-1}$ for cycle 1,2 and 3 , respectively. With the given values of $E, v$ and the measured values of $K_{T}^{r}$, stress reduction calculated for Mons were 1.06, 1.01, and 1.0 MPa. For the Kansas core, the thermo-elastic coefficients were not constant for each cycle such that the predicted values of the necessary side stress reduction were 0.36 , 0.24 and $0.11 \mathrm{MPa}$.

Table 3 Strain and thermal expansion coefficient measured from diameter changes during temperature reduction. *value from (Megawati et al., 2015) for Mons sample saturated with 0.657 M $\mathrm{NaCl}$, as that sample demonstrated the least dissolution. **value from (Megawati et al., 2015) for Kansas sample saturated with distilled water.

\begin{tabular}{|c|c|c|c|c|c|c|c|}
\hline Sample & $E(\mathbf{G P a})$ & $K_{\text {bulk }}(\mathrm{GPa})$ & $v$ & & $\varepsilon_{r}\left(\times 10^{-4}\right)$ & $K_{T}^{r}\left(\mathbf{K}^{-1}\right)$ & $\delta \sigma_{r}^{\prime}(\mathrm{MPa})$ \\
\hline \multirow{3}{*}{ M-10b } & \multirow{3}{*}{1.9} & \multirow{3}{*}{$0.8^{*}$} & \multirow{3}{*}{0.10} & Cooling 1 & 5.0 & $8.4 \cdot 10^{-6}$ & -1 \\
\hline & & & & Cooling 2 & 4.8 & $8.0 \cdot 10^{-6}$ & -1 \\
\hline & & & & Cooling 3 & 4.7 & $7.9 \cdot 10^{-6}$ & -1 \\
\hline \multirow{3}{*}{ K-21a } & \multirow{3}{*}{2.7} & \multirow{3}{*}{$1.5^{* *}$} & \multirow{3}{*}{0.20} & Cooling 1 & 1.1 & $1.8 \cdot 10^{-6}$ & -0.4 \\
\hline & & & & Cooling 2 & 0.73 & $1.2 \cdot 10^{-7}$ & -0.2 \\
\hline & & & & Cooling 3 & 0.33 & $5.5 \cdot 10^{-7}$ & -0.1 \\
\hline
\end{tabular}




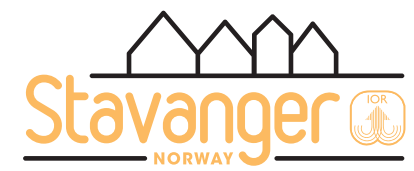

\section{The National \\ IOR Centre \\ of Norway

The experimental results of the side stress reduction cycles are presented in Table 4. To reach the target diameters at $30^{\circ} \mathrm{C}$, the side stress was reduced. For Mons, the side stress was reduced from 2 to the minimum value of $0.8 \mathrm{MPa}$. Within this stress window the diameter did not regain its value at $90^{\circ} \mathrm{C}$. As such, a linear relationship was used between diameter and side stress that enabled to predict side stress reductions of between -8.2 and -8.9 MPa to reach the target diameter (Table 4). Figure 5 is used to represent the corresponding results with respect to stress cycle values of $q$ and $p$ in relation to the shear failure line. For these experiments, the extrapolated values cannot be meaningful because shear failure would occur before zero radial strain is reached, and so the linearity between diameter and side stress would not longer apply (Figure 5 left).

Kansas chalk however, required less side stress reduction to reach the target diameter. Here, the side stress reduction could be measured directly. It was found that the side stress reduction needed was decreasing with each cycle from $-0.72,-0.44$ to $-0.20 \mathrm{MPa}$. The experimental values of side stress reduction for Kansas chalk are relatively close to the calculated values in Table 3. On the other hand, Mons chalk experimental values were much higher than theoretically predicted.

Table 4 Extrapolated (*) and measured radial stress change needed to restore diameter prior cooling. For Mons, radial stresses reduction was projected for the desired diameter using linear relationship between side stress changes from 1.2 to 0.8 MPa and diameter change

\begin{tabular}{c|c|c|c}
\hline & Cooling 1 & Cooling 2 & Cooling 3 \\
\hline Sample & $\boldsymbol{\delta} \boldsymbol{\sigma}_{\boldsymbol{r}}(\mathbf{M P a})$ & $\boldsymbol{\delta} \boldsymbol{\sigma}_{\boldsymbol{r}}(\mathbf{M P a})$ & $\boldsymbol{\delta} \boldsymbol{\sigma}_{\boldsymbol{r}}(\mathbf{M P a})$ \\
\hline $\mathrm{M}-10 \mathrm{~b}$ & $-8.9\left(^{*}\right)$ & $-8.2(*)$ & $-8.4(*)$ \\
\hline K-21a & -0.72 & -0.44 & -0.20 \\
\hline
\end{tabular}

The last part of the experiment was to investigate if the maximum shear strength of the sample was affected by the stress and temperature cycles. The red dot in Figure 5 (left) displays the shear strength required for the Mons sample. The Kansas chalk (Table 4) reaches the target diameter within the allowed confining pressure reduction. The maximum strength at which the sample fails is shown by the red dot in Figure 5 (right). Similar to Mons, the maximum shear strength is within the calculated error of the shear failure line (Figure 3). This indicate that the combined stress and temperature cycling had no significant effect on strength.
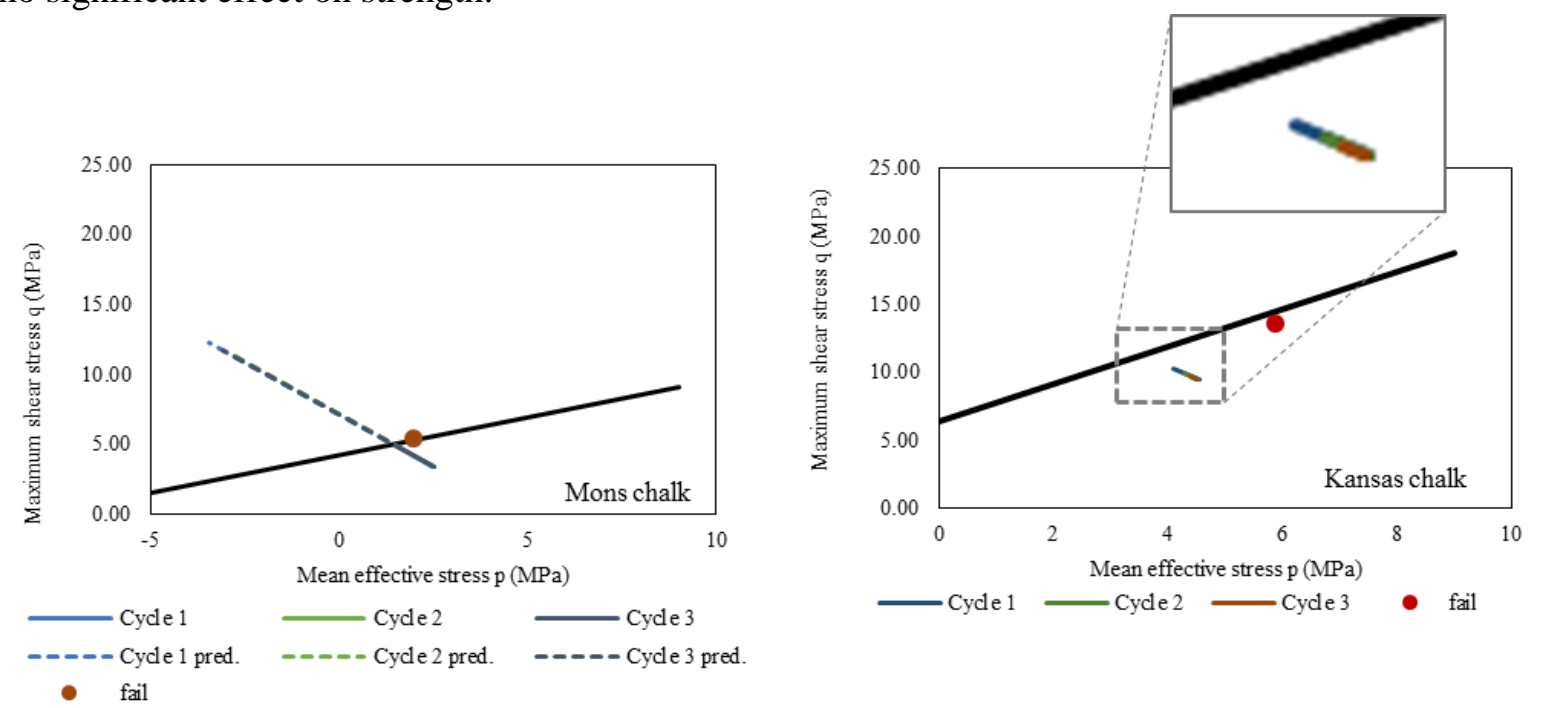

Figure 5 p-q diagram for Mons chalk (left) and Kansas chalk (right) at uniaxial strain conditions. Mons chalk experience much greater confining pressure reduction than Kansas to reach the target diameter, and hence crosses the shear failure line in order to maintain uniaxial strain condition. Kansas chalk did not cross the shear failure line before the target diameter was reached. 


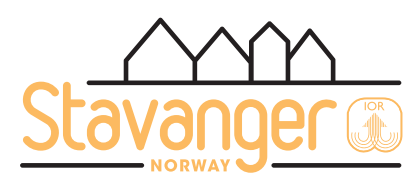

\section{The National \\ IOR Centre}

of Norway

\section{Discussion}

Uniaxial strain tests mimic reservoir behaviour, where the reservoir is free to deform vertically, but is constrained horizontally. During cooling, thermal contraction takes place, and to maintain the constant horizontal dimensions the radial stress must be reduced. This study examined if this change in radial stress was sufficient to cause chalk core failure, and if the behaviour changed as the chalk was repeatedly heated and cooled.

Two chalk types, Mons and Kansas were tested using the same set up and procedure. The impact of temperature was investigated at $70 \%$ of yield failure, keeping the side stress at $2 \mathrm{MPa}$. The axial yield stresses were higher for Kansas than for Mons, and thus were the axial overburden stresses, 11.8 and 5.3 MPa respectively. This lead to a lower stress ratio in Kansas (0.17) than Mons (0.37). This could explain why more permanent strain was accumulated in Kansas during the experiment, and the Mons sample behaved more elastically.

The side stress could only be lowered to $0.8 \mathrm{MPa}(0.1 \mathrm{MPa}$ above pore pressure). In order to restore the same diameter after temperature reduction from $90^{\circ} \mathrm{C}$ to $30^{\circ} \mathrm{C}$, the side stress had to be extrapolated for the Mons chalk, and it was sufficient to cross the shear failure line. Kansas chalk, on the other hand, was able to reach uniaxial strain conditions without crossing the shear failure line. The thermal radial contraction reduced from 1.8 to $0.55 \cdot 10^{-6} \mathrm{~K}^{-1}$ for each cycle. Consequently, the amount of confining pressure reduction decreases with each temperature cycle.

For both samples, the shear strength was not significantly different compared to the samples used to plot the shear failure, which were not exposed to temperature nor stress cycles.

The difference in behaviour of the two chalks may also be due to differing degrees of induration, and the different contributions from the forces that bind the grains together. Potentially, Mons stiffness and strength comes from electrostatic forces, as the temperature cycling does not seem to influence the stiffness and strength of the sample through the test. On the contrary, the contact cementation is more important for the $\mathrm{H} 3$ indurated Kansas chalk, as can be seen from the larger change in material property and accumulated strain for each cycle. This could indicate that once cementation is broken it cannot be re-established, resulting in permanent changes.

\section{Conclusion}

Two different chalks with different carbonate content and induration were tested in order to examine if temperature reduction could trigger shear failure. The extrapolated value of radial stress reduction for Mons indicates that $60^{\circ} \mathrm{C}$ temperature decrease was sufficient to cause shear failure while restoring the uniaxial strain conditions. The Mons sample did not demonstrate any change in either the thermal expansion coefficient, elastic stress-strain behaviour or strength due to three temperature and stress cycles. This could indicate that the forces that bind its grains together are at greater distance than the thermal expansion of each grain, and would not play any role in how the chalk is held together. On the contrary, the temperature reduction was not sufficient to cause the Kansas sample to fail, but the temperature cycles caused permanent deformation. This could indicate that the behaviour of Kansas chalk is dictated by forces at shorter distance ranges, such as cementation, and once those bonds were broken due to thermal expansion and contraction, and they did not re-establish.

\section{Acknowledgment}

The authors acknowledge the Research Council of Norway and the industry partners; ConocoPhillips Skandinavia AS, Aker BP ASA, Eni Norge AS, Maersk Oil Norway AS, DONG Energy A/S, Denmark, Statoil Petroleum AS, ENGIE E\&P NORGE AS, Lundin Norway AS, Halliburton AS, Schlumberger Norge AS, Wintershall Norge AS of The National IOR Centre of Norway for support. 


\section{Reference}

dos Reis, J.M.L. (2012) Effect of temperature on mechanical properties of polymer mortars. Materials Research, 15(4), 645-649

Fjær, E., Holt, R.M., Horsrud, P., Raaen, A.M. and Risnes, R. (2008) Petroleum Related Rock Mechanics, volume Developments in Petroleum Science 53. Elsevier Science, $2^{\text {nd }}$ edition.

Huang, S. and Xia, K. [2015] Effects of heat-treatment on the dynamic compressive strength of Longyou sandstone. Engineering Geology, 191, 1-7.

Lee, H.S, Lee, H., Park, Y. and Kwon, K. (1996) The mechanical and hydraulic characteristics of granite and gneiss under temperature variation. Eurock '96 Barla, 1371-1377.

Madland, M., Korsnes, R.I. and Risnes, R. (2002) Temperature effects in Brazilian, uniaxial and triaxial compressive tests with high porosity chalk. SPE Reservoir Evolution and Engineering, 74711.

Mavko, G., Mukerji, T., Dvornik, J. (2009) The Rock Physics Handbook, Tools for Seismic Analysis of Porous Media. Cambridge University Press, $2^{\text {nd }}$ edition.

Megavati, M., Madland, M.V. and Hiorth, A. (2015) Mechanical and physical behaviour of highporosity chalks exposed to chemical perturbation. Journal of Petroleum Science and Engineering, 133, 313-327.

Nagel, N.B. (2000) Compaction and subsidence issues within the petroleum industry: Wilmington to Ekofisk and beyond. Physics and Chemistry of the Earth, Part A: Solid Earth and Geodesy, 26, 3-14.

Nermoen, A., Korsnes, R.I., Fabricius, I.L. and Madland, M.V. (2016) Extending the effective stress relation to incorporate electrostatic effects. Society of Exploration Geophysicists, 5891149.

Richard, J., Suzun J.-P. and Machhour, L. (2005) Environmental and diagenetic records from a new reference section for Boreal realm: The Campanian chalk of the Mons basin (Belgium). Sedimetary Geology. 178, 99-111.

Rosenholtz, J.L. and Smith, D.T. (1949) Linear thermal expansion of calcite, var. Iceland Spar, and Yule marble. American Mineralogist, 34, 846-854.

Royer-Carfagni, G. (1999) Some considerations on the wrapping of marble facades: the example of Alvar Aalto's Finlandia Hall in Helsinki. Construction and Building Materials, 13, 449-457.

Sahrabi, M., Kechut, N.I., Riazi, M., Jamiolahmady, M., Ireland, S. and Robertson, G. (2011) Safe storage of CO-2 together with improved oil recovery by CO-2 enriched water injection. Chemical engineering research and design, 89, 1865-1872.

Yu, J., Chen, S., Chen, X., Zhang, Y. and Cai, Y. (2015) Experimental investigation on mechanical properties and permeability evolution of red sandstone after heat treatment. Journal of Zhejiang University - SCIENCE A (Applied Physics and Engineering), 16 (9), 749-759. 